\title{
Analysis of Influence Factors for Low-Carbon Logistics
}

\author{
Yu Nie, Zhongdong Xiao, Binbin Cao, and Guanghui Zhou
}

\begin{abstract}
Global warming has become a severe problem of the environment. Logistics industry has been the second largest industry to emit the green house gas. So analyze the influence factors of logistics industry and control them can reduce carbon emission significantly. The paper collects the data of energy consumption, increase value, etc, to calculate the carbon emission and carbon emission intensity of logistics industry. Then using the Path Analysis Model, four important influence factors and their impact path are revealed. The energy structure and productive dimension have positive impact on carbon emission while energy efficiency and development level have negative impact on carbon emission. Development level has positive effect on energy efficiency.
\end{abstract}

Index Terms-Carbon emission, energy structure, energy efficiency, productive dimension, development level.

\section{INTRODUCTION}

Global warming has become one of the most serious problems. In 1896, Irish chemist Arrhenius proposed that fossil fuel burning would increase carbon intensity of atmosphere. After that, more and more studies show that global warming is cyclical and caused by human activities. Greenhouse gas emissions are the main culprit in global warming. Among varieties of greenhouse gases, carbon dioxide, as the most important one, accounts for more than two thirds of the total pollution. Carbon dioxide has a longer survival life in the atmosphere for 50 to 200 years. Carbon dioxide, which is just like an invisible glass, can absorb the heat and stop the heat radiating to the outer space.

In the 1920s, American scholar Arch first proposed the term of Physical Distribution. People used it for a long time until 1980s. The Council of Logistics Management changed it to Logistics and expanded its range of application. The Council described the definition of logistics as an important part of the produce chain which is based on satisfying the requirement of the customers to scheme and control the information of the product, marketing and service after selling [1].

In the reality, there are close relationship between the logistics system and the environment. The logistics system is a complicate, dynamic and open system which includes the manufacture, distribution and consumption. The logistics system is also a cyclical system contained economic system and biotical system.

Green logistics is based on the sustainable economy and

Manuscript received February 28, 2015; revised July 17, 2015.

$\mathrm{Yu}$ Nie, Zhongdong Xiao, and Binbin Cao are with the School of Management, Xi'an Jiaotong University, Xi'an, China (e-mail: yunie@foxmail.com,xzd@mail.xjtu.edu.cn, 1029326989@qq.com).

Zhou Guanghui is with the School of Mechanical Engineering, Xi'an Jiaotong University, Xi'an, China (e-mail: ghzhou@ mail.xjtu.edu.cn). aims to construct a circular and cyclical logistics system in order to protect the environment and build a harmonious society. Scholar Wang CQ revealed that the object of the green logistics is to decrease the pollution of the environment and the consumption of the resource. The implement of the logistics, such as transportation, storage, circulation and manufacture, needs to apply advanced logistics technique and make a long-term plan. Zeng GP showed that green logistics is a process to satisfy the demand of the consumers and link the suppliers and the consumers. Green logistics, which delivers green goods and service, improves the logistics system to a symbiotic-environment logistics management system [2].

Low carbon logistics is a new concept raised after the low carbon concept. There are few studies about low carbon logistics at home and abroad, so its definition is ambiguous. Through learning low-carbon economy and green logistics concepts, low-carbon logistics can be defined as: a kind of logistics mode which applies advanced technology and integrates different resource to improve efficiency and reduce the carbon emission. In a word, low carbon logistics focuses on carbon emission and aims to reduce the carbon emission [3].

The logistics industry is a bridge to connect the production and consumption as well as a pillar to support the manufacturing and commercial industry. As the demand of logistics increases, the influence of the logistics system to the environment becomes more obvious. The carbon emissions of all sectors of the logistics have become greater. As we all know, with the rapid development of China's economy and the sharp rise in demand for logistics, the fossil energy consumption of logistics industry has expanded to a larger scale [4].

According to the energy sub-sector consumption data of the National Bureau of Statistics, the proportion of energy consumption of logistics industry over the past decade is about 7\%. It will bring more carbon emission. In 2013, the energy consumption of logistics industry, which is the second largest industry to consume fossil energy, has risen to 303.85 million tons of standard coal. So we must to pay attention to carbon emission of logistics industry and make effort to reduce the carbon emission.

The paper analyzes the situation of carbon emission of logistics industry and confirms the influence factors of the carbon emission to help the relative institutions to control the green house gas pollution and protect the environment.

\section{CARBON EMISSION ANALYSIS OF LOGISTICS INDUSTRY}

The direct monitoring carbon emission data can't be found because China has not established a sound monitoring system to survey the data. According to the result of the forth 
estimation report of IPCC, most of the evaluation research at present base on the estimation of the energy consumption because the main source of the green house gas is the burning of fossil energy resources. The formula is as follows.

$$
C=\sum C i=\sum \frac{E i}{E} \times \frac{C i}{E i} \times E=\sum S i \times F i \times E
$$

where

$C$ is carbon emission;

$C i$ is carbon emission of energy $i$;

$E$ is the total consumption of energy;

$E i$ is the consumption of energy;

$S i$ is the proportion of energy $i$ in the total energy;

$F i$ is the carbon emission coefficient of energy $i$.

The consumption data of different kind of energy from 1980 to 2013 can be checked in China Statistic Yearbook, Energy Statistic Yearbook and China Logistics Yearbook. Fi is from the Energy Research Institute of National Development and Reform Commission which is a national level research institute of the energy. The value of $F i$ is as follows, see in Table I.

TABLE I: CARBON EMISSION COEFFICIENTS OF DIFFERENT ENERGY

\begin{tabular}{lllll}
\hline \hline Carbon Emission Coefficient & Coal & Oil & $\begin{array}{l}\text { Natural } \\
\text { Gas }\end{array}$ & Elec \\
\hline $\begin{array}{l}F i \\
(t C / \text { Ten Thousand Tons } \\
\text { of Standard Coal })\end{array}$ & 0.7476 & 0.5825 & 0.4435 & 0 \\
\hline \hline
\end{tabular}

TABLE II: CARBON EMISSION DATA OF LOGISTICS INDUSTRY

\begin{tabular}{|c|c|c|c|c|}
\hline Year & $\begin{array}{l}\text { Carbon } \\
\text { Emission } \\
\text { of Coal }\end{array}$ & $\begin{array}{l}\text { Carbon } \\
\text { Emission } \\
\text { of Oil }\end{array}$ & $\begin{array}{l}\text { Carbon } \\
\text { Emission of } \\
\text { Natural Gas }\end{array}$ & $\begin{array}{l}\text { Total } \\
\text { Carbon } \\
\text { Emission }\end{array}$ \\
\hline 1980 & 1446.16 & 530.95 & 0.31 & 1977.42 \\
\hline 1981 & 1558.75 & 530.95 & 0.31 & 2090.01 \\
\hline 1982 & 1624.68 & 540.50 & 0.27 & 2165.45 \\
\hline 1983 & 1638.59 & 584.07 & 0.35 & 2223.02 \\
\hline 1984 & 1704.23 & 619.61 & 0.35 & 2324.19 \\
\hline 1985 & 1724.79 & 685.25 & 0.35 & 2410.40 \\
\hline 1986 & 1715.74 & 801.35 & 0.44 & 2517.53 \\
\hline 1987 & 1675.75 & 860.06 & 0.22 & 2536.03 \\
\hline 1988 & 1689.13 & 907.07 & 0.49 & 2596.68 \\
\hline 1989 & 1707.59 & 952.15 & 0.31 & 2660.06 \\
\hline 1990 & 1615.49 & 980.46 & 0.84 & 2596.80 \\
\hline 1991 & 1513.74 & 1089.97 & 0.53 & 2604.25 \\
\hline 1992 & 1402.42 & 1214.40 & 0.49 & 2617.31 \\
\hline 1993 & 1308.67 & 1453.92 & 0.35 & 2762.95 \\
\hline 1994 & 1400.55 & 1369.05 & 0.58 & 2770.18 \\
\hline 1995 & 983.17 & 1668.05 & 0.70 & 2651.91 \\
\hline 1996 & 879.10 & 1711.21 & 1.78 & 2592.09 \\
\hline 1997 & 1069.82 & 2174.47 & 1.64 & 3245.93 \\
\hline 1998 & 1039.61 & 2472.89 & 1.63 & 3514.13 \\
\hline 1999 & 967.62 & 2915.00 & 2.13 & 3884.75 \\
\hline 2000 & 852.22 & 3209.23 & 2.58 & 4064.02 \\
\hline 2001 & 785.64 & 3316.12 & 2.64 & 4104.40 \\
\hline 2002 & 788.72 & 3586.22 & 2.83 & 4377.76 \\
\hline 2003 & 797.94 & 4131.81 & 3.02 & 4932.77 \\
\hline 2004 & 622.09 & 5021.49 & 4.95 & 5648.54 \\
\hline 2005 & 609.55 & 5655.19 & 7.29 & 6272.02 \\
\hline 2006 & 541.86 & 6389.54 & 7.65 & 6939.04 \\
\hline 2007 & 512.44 & 7130.46 & 7.49 & 7650.40 \\
\hline 2008 & 497.46 & 7702.26 & 31.73 & 8231.45 \\
\hline 2009 & 479.13 & 7859.01 & 40.39 & 8378.53 \\
\hline 2010 & 477.89 & 8626.37 & 47.32 & 9151.58 \\
\hline 2011 & 482.84 & 9294.15 & 61.36 & 9838.35 \\
\hline 2012 & 480.36 & 9628.05 & 68.38 & 10176.78 \\
\hline 2013 & 479.13 & 9794.99 & 71.89 & 10346.00 \\
\hline
\end{tabular}

After calculation, the carbon emission data of logistics industry from 1980 to 2013 are shown in Table II.

Carbon emission intensity refers to the amount of carbon emissions of per unit of output in a given period, reflecting the degree of economic dependence on carbon emissions. By collecting logistics industry value over the years 1980-2013, the paper shows the carbon emission intensity of logistics industry. In order to maintain comparability of data between different years, the output values of different years are converted to comparable price value. The result is in Table III.

TABLE III: CARBON EMISSION INTENSITY OF LOGISTICS INDUSTRY

\begin{tabular}{|c|c|c|c|c|}
\hline Year & $\begin{array}{l}\text { Increase Value } \\
\text { (One Hundred } \\
\text { Million Yuan) }\end{array}$ & $\begin{array}{l}\text { Carbon } \\
\text { Emission } \\
(10000 \text { Tons })\end{array}$ & $\begin{array}{l}\text { Retail } \\
\text { Price } \\
\text { Index }\end{array}$ & $\begin{array}{l}\text { Carbon Emission } \\
\text { Intensity } \\
(t / 10000 \text { Yuan })\end{array}$ \\
\hline 1980 & 213.36 & 1977.42 & 100.00 & 9.27 \\
\hline 1981 & 220.70 & 2090.01 & 106.00 & 10.04 \\
\hline 1982 & 246.86 & 2165.45 & 106.00 & 9.86 \\
\hline 1983 & 274.95 & 2223.02 & 107.00 & 9.72 \\
\hline 1984 & 338.52 & 2324.19 & 107.00 & 8.83 \\
\hline 1985 & 421.72 & 2410.40 & 108.80 & 8.00 \\
\hline 1986 & 498.84 & 2517.53 & 107.00 & 7.56 \\
\hline 1987 & 568.32 & 2536.03 & 106.00 & 7.08 \\
\hline 1988 & 685.74 & 2596.68 & 105.00 & 6.31 \\
\hline 1989 & 812.74 & 2660.06 & 104.00 & 5.67 \\
\hline 1990 & 1167.03 & 2596.80 & 102.10 & 3.94 \\
\hline 1991 & 1420.30 & 2604.25 & 104.00 & 2.62 \\
\hline 1992 & 1688.98 & 2617.31 & 106.00 & 3.02 \\
\hline 1993 & 2173.99 & 2762.95 & 108.00 & 2.68 \\
\hline 1994 & 2787.89 & 2770.18 & 110.00 & 2.30 \\
\hline 1995 & 3244.30 & 2651.91 & 114.80 & 2.18 \\
\hline 1996 & 3782.16 & 2592.09 & 106.10 & 1.93 \\
\hline 1997 & 4148.57 & 3245.93 & 100.80 & 2.23 \\
\hline 1998 & 4660.90 & 3514.13 & 97.40 & 2.09 \\
\hline 1999 & 5175.17 & 3884.75 & 97.00 & 2.02 \\
\hline 2000 & 6160.95 & 4064.02 & 98.50 & 1.75 \\
\hline 2001 & 6870.25 & 4104.40 & 99.20 & 1.57 \\
\hline 2002 & 7492.95 & 4377.76 & 98.70 & 1.35 \\
\hline 2003 & 7913.19 & 4932.77 & 99.90 & 1.61 \\
\hline 2004 & 9304.39 & 5648.54 & 102.80 & 1.62 \\
\hline 2005 & 10666.16 & 6272.02 & 100.80 & 1.58 \\
\hline 2006 & 12182.98 & 6939.04 & 101.00 & 1.54 \\
\hline 2007 & 14601.04 & 7650.40 & 103.80 & 1.47 \\
\hline 2008 & 16362.50 & 8231.45 & 105.90 & 1.50 \\
\hline 2009 & 16727.11 & 8378.53 & 98.80 & 1.47 \\
\hline 2010 & 19132.19 & 9151.58 & 103.10 & 1.45 \\
\hline 2011 & 22432.84 & 9838.35 & 104.90 & 1.40 \\
\hline 2012 & 24660.00 & 10176.78 & 102.00 & 1.34 \\
\hline 2013 & 27283.00 & 10346.00 & 101.40 & 1.25 \\
\hline
\end{tabular}

The table shows that carbon emission intensity decreases over time. In 1980, carbon emission intensity is 9.27, while in 2013 , it drops to 1.25 . The change indicates that the efficiency of energy of logistics becomes higher and higher as time goes by. It may be because of the development of the technology and the awareness of protecting the environment.

\section{PATH ANALYSIS OF CARBON EMISSION LOGISTICS INDUSTRY}

\section{A. Hypotheses}

In order to study the high-carbon impact mechanism of logistics industry, the paper uses path analysis method. Path analysis, which is a modeling approach to analyze the causality relationship, was first proposed by biologists Wright in 1921. It can help us to recognize the relationship between different factors. 
Of course, the factors that affect high carbon emission of logistics industry includes supervision of government and public, reverse logistics development, recycle technology development, etc. Because of the lack of these data and the consideration of importance, the paper chooses the most important factors to analyze and build their relationship.

Firstly, in the fossil fuel-based energy structure, the proportion of clean energy of logistics industry is very small. So the logistics industry of our country mainly consumes the fuel energy to match the vehicle mode and the fuel energy consumption keeps the ratio of $70 \%$ in recent 5 years. Especially, the proportion of diesel and gasoline consumption is up to $50 \%$. The fossil fuel-based energy structure has become the main factor to influence the carbon emission of logistics industry [5].

Secondly, because of the transportation mode, logistics nodes optimization, etc, the energy efficiency of logistics industry is still low. In addition, from the view point of logistics, domestic logistics industry starts lately and lowly and is still in its early stage of development. So there is a big gap in energy efficiency between the domestic logistics and international logistics. And the energy efficiency, as a main factor, can influence the carbon emission severely [6].

Thirdly, the development level can influence the carbon emission directly. The development level reflects the carbon emission situation of logistics industry. If the development level is higher, the carbon emission will be more [7].

Last but not the least, with the rapid development of domestic economy, the demand of the logistics service is increasing in recent years. The increase value of logistics industry has risen to 2728.3 billion Yuan. The productive dimension of logistics industry continues increasing and has become a main factor to impact the carbon emission [8].

The high-pollution and non-renewable energy structure, low energy efficiency, high development level and production capacity expansion are main reasons to impact the carbon emission of logistics industry.

So the paper proposes these hypotheses:

Hypothesis 1: Energy structure of logistics industry has positive impact to carbon emission. The more non-renewable energy the logistics industry uses, the more carbon the logistics industry will emit [9].

Hypothesis 2: Energy efficiency of logistics industry has negative impact to carbon emission. The higher the energy efficiency is, the less carbon the logistics industry will emit [10].

Hypothesis 3: Development level of logistics industry has positive impact on the energy efficiency of logistics industry.

Hypothesis 4: Development level of logistics industry has negative impact on carbon emission of logistics industry.

Hypothesis 5: Productive dimension of logistics industry has positive impact on carbon emission of logistics industry.

\section{B. Model Building}

According to these hypotheses, the model can be built as in Fig. 1.

In the model, the arrow means the causality relationship. $e_{1}$ and $e_{2}$ represent the residual which can't be explained by the model. There are 7 variables in the model. $x_{1}, x_{2}, x_{3}, x_{4}$ and $y$ is the observable variables while $e_{1}$ and $e_{2}$ are unobservable variables. There are 5 path coefficients, which are regression coefficients, to be estimated. They are $w_{1}, w_{2}, w_{3}, w_{4}$ and $w_{5}$. $c_{1}, c_{2}$ and $c_{3}$ are the covariance and $v_{1}, v_{2}, v_{3}, v_{4}$ and $v_{5}$ are variance. According to the law $T$, if $T<(p+q)(p+q+1) / 2$, the model is a recognizable model. In the model, $T$ equals to 15 , while $(p+q)(p+q+1) / 2=18$. So the model is recognizable.

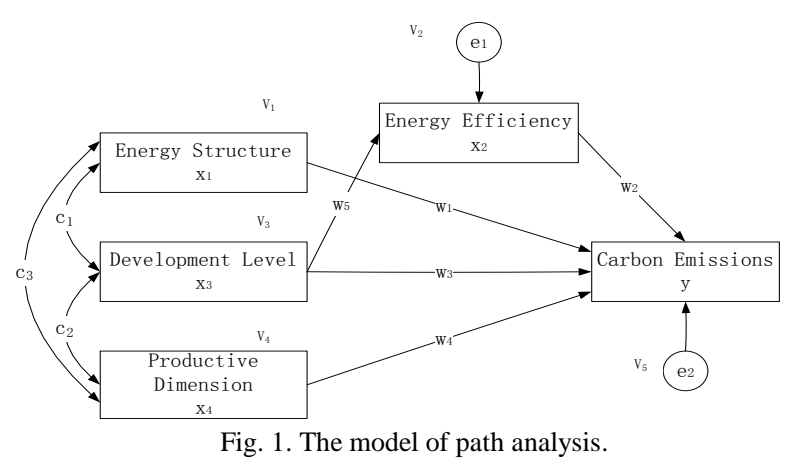

In the initial model diagram, relative main factors, variables, computing method and the basic data are shown in Table IV.

TABLE IV: MAIN FACTORS, VARIABLES, COMPUTING METHOD AND THE BASIC DATA OF THE MODEL

\begin{tabular}{|c|c|c|c|}
\hline Main Factor & Variable & Computing Method & Basic Data \\
\hline $\begin{array}{l}\text { Energy } \\
\text { Structure }\end{array}$ & $X_{1}$ & $\begin{array}{l}\text { Fuel energy } \\
\text { consumption is } \\
\text { divided by total } \\
\text { energy consumption }\end{array}$ & $\begin{array}{l}\text { consumption of coal, } \\
\text { oil and natural gas; } \\
\text { total energy } \\
\text { consumption }\end{array}$ \\
\hline $\begin{array}{l}\text { Energy } \\
\text { Efficiency }\end{array}$ & $X_{2}$ & $\begin{array}{l}\text { Total energy } \\
\text { consumption is } \\
\text { divided by increase } \\
\text { value }\end{array}$ & $\begin{array}{l}\text { Increase value; total } \\
\text { energy consumption }\end{array}$ \\
\hline $\begin{array}{l}\text { Development } \\
\text { Level }\end{array}$ & $X_{3}$ & $\begin{array}{l}\text { Increase value is } \\
\text { divided by GDP }\end{array}$ & Increase value; GDP \\
\hline $\begin{array}{l}\text { Productive } \\
\text { Dimension }\end{array}$ & $X_{4}$ & Direct value & $\begin{array}{l}\text { fixed-asset investment } \\
\text { of logistics industry }\end{array}$ \\
\hline $\begin{array}{l}\text { Carbon } \\
\text { Emission }\end{array}$ & $y$ & $\begin{array}{l}\text { Energy consumption } \\
\text { multiplied by carbon } \\
\text { emission coefficient }\end{array}$ & $\begin{array}{l}\text { Consumption of coal, } \\
\text { oil and natural gas; } \\
\text { carbon emission } \\
\text { coefficient }\end{array}$ \\
\hline
\end{tabular}

By calculating the estimated value, the result reveals that the chi-square value is 2.647 , df is 2 , the significance level is 0.02 which is less than 0.05 . So the model is well fit to the observed data. The output of the model can be displayed as follows, see in Table V.

TABLE V: THE OUTPUT OF THE MODEL

\begin{tabular}{lllll}
\hline \hline Path & Estimate & S.E. & C.R. & p \\
\hline $\begin{array}{l}\text { Energy Structure — carbon } \\
\text { emission }\end{array}$ & 1925.15 & 363.32 & 2.632 & 0.031 \\
$\begin{array}{l}\text { Energy Efficiency — carbon } \\
\text { emission }\end{array}$ & -1215.26 & 170.12 & 4.723 & $* * *$ \\
$\begin{array}{l}\text { Development Level - } \\
\text { carbon emission }\end{array}$ & -2528.31 & 276.32 & 2.163 & 0.027 \\
$\begin{array}{l}\text { Productive Dimension } \\
\text { carbon emission } \\
\begin{array}{l}\text { Development Level - Energy } \\
\text { Efficiency }\end{array}\end{array}$ & 5253.12 & 576.41 & 6.52 & $* * * *$ \\
\hline \hline
\end{tabular}

The result shows that energy structure and productive dimension have positive impact on carbon emission while energy efficiency and development level have negative impact on carbon emission. Development level has positive effect to energy efficiency. 


\section{CONCLUSION}

Path analysis shows that the energy structure of logistics industry, energy efficiency, development level as well as productive dimension have a strong influence on carbon emission. Among them, productive dimension and development level have the most important impact on the carbon emission of logistics industry. Also, we can't neglect the influence effects of energy structure and energy efficiency. So we can take some measure from these aspects to handle the green house gas pollution.

At first, energy structure should be changed to use more clean energy because more fossil fuel means more carbon emission. Second, we should try our best to improve the energy efficiency. More high level technology should be used to cut the carbon emission. At the same time, research about cyclic utilization and energy reuse should be paid more attention. Third, we should make our effort to raise development level of logistics industry and improve the healthy development of the industry, such as optimizing the process and improving the information level. Finally, the productive dimension should be controlled in order to make sure the industry to develop more stably.

Carbon emission has drawn more attention these years. As the development of logistics industry of China, the environment problem has become a severe problem. It indicates the presence of incompatibility between the development of logistics industry and the current environment. In a short time, the carbon emission will keep increasing and logistics industry will bear more pressure to reduce the carbon emission.

\section{ACKNOWLEDGMENT}

Gratitude is extended to the National Natural Science Foundation of China (Grant No.: 71171156; 51175414).

\section{REFERENCES}

[1] X. Xu, "Research on construction and characteristics of low carbon logistics system," Commercial Times, no. 10, pp. 23-24, 2011.

[2] X. Zhong, "Development of low carbon logistics factors and countermeasures," Reform Strategy, no. 1, pp. 51-52, 2012.

[3] J. Sarkis, Q. Zhu, and K. H. Lai, "An organizational theoretic review of green supply chain management literature," International Journal of Production Economics, vol. 130, issue 1, pp. 1-15, 2011.

[4] S. Ubeda, F. J. Arcelus, and J. Faulin, "Green logistics at Eroski: A case study," International Journal of Production Economics, vol. 131, issue 1, pp. 44-51, 2011.

[5] X. Y. Liu, "Analysis of the development of low carbon logistics based on a low carbon economy," in Proc. the International Conference on Low-carbon Transportation and Logistics and Green Buildings, 2013, pp. 673-679.

[6] H. J. Wu and S. C. Dunn, "Environmentally responsible logistics systems," International Journal of Physical Distribution and Logistics Management, vol. 25, pp. 20-38, 1995.

[7] A. Mckinnon, "Green logistics: The carbon agenda," Electronic Scientific Journal of Logistics, vol. 6, no. 1, pp. 1-9, 2010.

[8] J. Liu and K. Han, "Establishment of logistics system in low-carbon economy," Logistics Technology, vol. 32, pp. 77-79, 2013.

[9] M. Yang and Y. Tian, "Establishment and application of logistics enterprises' low-carbon factors index system," in Proc. the $2^{\text {nd }}$
International Conference on Logistics, Informatics and Service Science (LISS' 12), Dec. 2012, pp. 401-407.

[10] Y. Wang, T. Lu, and C. Zhang, "Integrated logistics network design in hybrid manufacturing/remanufacturing system under low-carbon restriction," in Proc. the $2^{\text {nd }}$ International Conference on Logistics, Informatics and Service Science (LISS' 12), Dec. 2012, pp. 111-121.

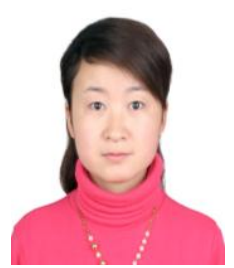

Yu Nie was born in Gansu province of China on April 14,1984 . She received her bachelor degree in industry engineering from Xi'an Jiaotong University in 2007. Then she received her master degree in management science and engineering from Xi'an Jiaotong University in 2011. Since September 2014, she has been a $\mathrm{PhD}$ candidate of management science and engineering in Xi'an Jiaotong University. Her major field is supply chain management.

She has published 3 articles: 1). "Usability assessment of the personal e-bank," Chinese Journal of Ergonomics, vol. 19, pp. 63-67, 2013. 2). "Analysis on straw purchasing model based on the cost," Science and Management, pp. 18-20, 2010. 3). "Study on straw purchasing mode of Zaozhuang Shiliquan power plant," Science and Management, vol. 6, pp. 46-50, 2009. Her current and previous research interest is supply chain management and green logistics.

Dr. Nie got the first class of national scholarship in Xi'an Jiaotong University in 2004, the second-class scholarship for master in Xi'an Jiaotong University from 2008 to 2011, and the gold award of the seventh chanllenging cup college student's business planning completion in Xi'an Jiaotong University in 2011.

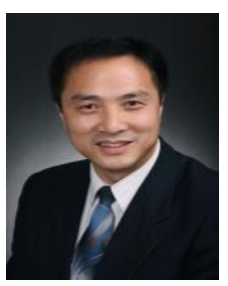

Zhongdong Xiao was born in Hunan province, China in October, 1968. He received the bachelor degree in economic management in 1991 from the Northwest University. Then he got the master degree in economic management in 1996 from Northwest University. In 2002, he received his $\mathrm{PhD}$ degree in management science and engineering from Xi'an Jiaotong University. His major field is theory and application of ecological industry.

Professor Xiao has worked in Xi'an Jiaotong University from 1996. He has published many articles, e.g. 1). "Using modified Barabási and Albert model to study the complex logistic network in eco-Industrial systems," International Journal of Production Economics, vol. 140, issue 1, pp. 295-304, 2012. 2). "A radio frequency identification based optimal material delivery method for digital plant production," Int. J. of Computer Integrated Manufacturing, vol. 24, issue 5, pp. 493-505, 2011. 3). "Dynamic job rescheduling using RFID technology," International Journal of Internet Manufacturing and Services, vol. 3, no.1, pp 42-58, 2011.

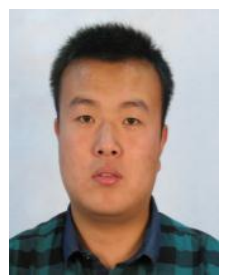

Binbin Cao was born in Gansu province, China on November 12, 1989. He got the bachelor degree in engineering management from China University of Petroleum (East China) in 2012. Since September 2012, he is pursuing his $\mathrm{PhD}$ degree in management science and engineering from Xi'an Jiaotong University. His research areas are supply chain management \& logistics management and environmental regulations.

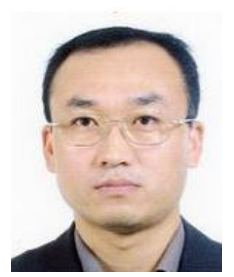

Guanghui Zhou was born in Hunan province of China. He received his bachelor degree in mechanical engineering in 1996, from Xi'an Jiaotong University. Then he got the master degree in mechanical engineering from Xi'an Jiaotong University in 1999. In July 2003, he received his $\mathrm{PhD}$ degree in mechanical engineering from Xi' an Jiaotong University. His major field is optimization design of complex mechatronic products. Professor Zhou has worked in Xi'an Jiaotong University from 2004. He has published many articles about mechanical engineering. 


\section{Energy-Saving Technology}


